Biodiversity and Conservation

\title{
Long-term bird colonization and turnover in restored woodlands
}

David B. Lindenmayer ${ }^{\mathrm{a}, \mathrm{b}, \mathrm{c}}$, P.W. Lane ${ }^{\mathrm{a}}$, P.S. Barton ${ }^{\mathrm{a}}$, Mason Crane ${ }^{\mathrm{a}}$, Karen Ikin ${ }^{\mathrm{a}, \mathrm{b}, \mathrm{c}}$, Damian Michael $^{\mathrm{a}, \mathrm{c}}$, and Sachiko Okada ${ }^{\mathrm{a}}$

${ }^{a}$ Fenner School of Environment and Society; ${ }^{\mathrm{b}}$ ARC Centre of Excellence for Environmental Decisions; ${ }^{\mathrm{c}}$ National Environmental Science Program Threatened Species Recovery Hub. The Australian National University, Canberra, ACT 2601, Australia.

Corresponding author: David Lindenmayer, Email: david.lindenmayer@anu.edu.au; Tel: +61 2 61250654; Fax: +61 261250746.

Word Count: 7390 words

Running title: Bird species colonization of replanted woodlands 


\section{Abstract}

2 The long-term effectiveness of restored areas for biodiversity is poorly known for the majority of restored ecosystems worldwide. We quantified temporal changes in bird

4 occurrence in restoration plantings of different ages and geometries, and compared observed

5 patterns with a reference dataset from woodland remnants on the same farms as our plantings.

6 Over time, bird species richness remained unchanged in spring but exhibited modest

7 increases in winter. We found that wider plantings supported significantly greater bird

8 species richness in spring and winter than narrow plantings. There was no evidence of a

$9 \quad$ significant interaction between planting width and time.

10 We recorded major temporal changes in the occurrence of a range of individual species that

11 indicated a clear turnover of species as plantings matured. Our results further revealed marked differences in individual species occurrence between plantings and woodland remnants. Life-history attributes associated with temporal changes in the bird assemblage were most apparent in winter survey data, and included diet, foraging and nesting patterns, movement behaviour (e.g. migratory vs dispersive), and body size.

Differences in bird assemblages between plantings of different ages suggest that it is important that farms support a range of age classes of planted woodland, if the aim is to maximize the number of native bird species in restored areas. Our data also suggest that changes in the bird species occupying plantings of different ages can be anticipated in a broadly predictable way based on planting geometry (especially width) and key life-history attributes, particularly movement patterns and habitat and diet specialisation. 


\section{Introduction}

Millions of hectares of land worldwide are degraded (World Resources Institute 2011; Stanturf et al 2014) leading to a loss of biodiversity (Clewell and Aronson 2007; Suding 2011). In response, billions of dollars are being spent annually by goverments and organisations on vegetation restoration in an effort to tackle this problem (Hajkowicz 2009; Aronson and Alexander 2013; Kimball et al 2015). However, the effectiveness of restoration efforts for biodiversity needs to be carefully quantified (Rey Benayas et al 2009) as it can be unclear whether the biota inhabiting replanted areas is similar to that of intact areas (e.g. Catterall et al 2012), or whether it is on a quite different trajectory (Wilkins et al 2003; Brady and Noske 2009).

Species colonization of planted vegetation is a core assumption of the restoration approach (Reay and Norton 1999; Barrett et al 2008; Catterall et al. 2012). But the extent to which this assumption holds for real-world restoration efforts needs to be quantified (Hilderbrand et al 2005; Mossman et al 2012). Indeed, the medium- to long-term effectiveness for biodiversity of restored areas is often poorly documented, particularly where vegetation has been deliberately replanted (but see for example Nichols and Grants 2007; Pywell et al 2011; Menke et al 2015). This is a major knowledge gap as short-term responses may not be a good predictor of long-term restoration success (Vesk et al 2008).

There is a range of other significant knowledge gaps associated with the effectiveness of restored areas for biodiversity conservation. First, it remains unclear how patterns of species richness and patterns of occurrence of individual species within restored areas may change over time. Some ecological theories suggest that new species will be added to a recovering ecosystem as time elapses since disturbance (Pulsford et al 2016) or the commencement of restoration efforts (Cristescu et al 2012). Conversely, species richness in restored areas may remain unchanged over time, consistent with the general findings from a 
meta-analysis of time-series datasets on biodiversity from an array of disturbed ecosystems worldwide (Dornelas et al 2014). In addition, succession theory suggests that species may establish in an ecosystem when the vegetation structure and composition first meets their habitat requirements (Pulsford et al. 2016). Species may then decline or be excluded when the vegetation structure and composition changes and/or better-suited species outcompete them (Fox et al 2003). In the case of restored areas, vegetation height, structure and plant species composition may change over time (Vesk et al. 2008; Brady and Noske 2009) and this may influence the occurrence of biota.

A second significant knowledge gap associated with the effectiveness of restored areas for biodiversity concerns a paucity of information on relationships between the geometry of restored areas (e.g. size, width) and temporal changes in species richness and the occurrence of individual species. A range of general landscape ecology theories (e.g. island biogeography theory, edge-effects theory and habitat heterogeneity theory; reviewed by Lindenmayer and Fischer (2006)) suggest that larger and wider plantings should support more bird species. In addition, area-sensitive species may be likely to colonize larger, wider plantings more quickly than smaller and narrower plantings.

A final important knowledge gap is the paucity of studies examining relationships between life history attributes of biota and temporal changes in occupancy of restored areas. Several studies have quantified trait-based relationships of species with the time elapsed since disturbance (e.g. Langlands et al 2012). The performance filtering hypothesis (Mouillot et al 2012; Barnagaud et al 2014) suggests that species with particular functional traits are likely to be lost or gained in landscapes undergoing change (Newbold et al 2013), including intensively managed agricultural ecosystems (Tscharntke et al 2008; Hanspach et al 2012). To address the key knowledge gaps outlined above, here we quantify temporal changes in bird species richness and the occurrence of individual species between 2002 and 2013 in 
woodland restoration sites (hereafter termed "plantings") in south-eastern Australia. We compared these patterns with that of bird species richness and occurrence in "reference sites" comprised of remnant woodland patches (hereafter termed "remnants") surveyed at the same time and on the same farms as the planting sites. Specifically, we posed the following five questions:

Question 1. Does bird species richness in plantings change over time? Specifically, we tested the hypothesis that species richness would be greatest in the oldest plantings. At the outset of our investigation, we also postulated that the bird species richness of older plantings would more closely approximate that of remnant ("benchmark") sites than younger plantings.

\section{Question 2. Does planting geometry influence temporal changes in bird species richness? We} explicitly quantified relationships between planting geometry and changes in various measures of bird biota over time. We predicted that larger and wider plantings should be characterised by faster rates of increase in species richness than narrow plantings. That is, we hypothesized an interaction between planting age, planting geometry and bird species richness. We also quantified relationships between birds and the geometry of woodland remnants for subsequent qualitative comparison with planting geometry effects.

Question 3. Are there changes in the occurrence of individual bird species over time? We predicted temporal changes in the occurrence of individual bird species within plantings and that these changes would be influenced by temporal changes in vegetation structure. We also quantified temporal patterns of change in individual bird species within patches of remnant native woodland, and compared them with the temporal patterns of species occurrence in plantings.

\section{Question 4. Does planting geometry influence temporal changes in occurrence of individual}

bird species? We quantified individual bird species responses to time, planting geometry, and their interaction. We predicted that area-sensitive woodland bird species (Montague-Drake et 
100

101

102

103

104

105

106

107

108

109

110

111

112

113

114

115

116

117

118

119

120

121

122

123

al. 2009) would colonize larger, wider plantings more quickly than smaller and narrower plantings.

\section{Question 5. Are temporal changes in species' identities within plantings linked with} particular kinds of life-history attributes? At the outset of our investigation, we postulated that different functional groups of birds would be associated with plantings of different ages. This was because of temporal changes in such features as vegetation height and structure, the suitability of nesting sites, and food availability (e.g. insect prey) (Gibb and Cunningham 2010) - all of which can be important for birds.

Restoration of degraded ecosystems is a major global issue (Rey Benayas et al. 2009;

Suding 2011; Kimball et al. 2015). The outcomes of the long-term work that we report here are important for informing decisions about restoration efforts and setting expectations for the time-scale required for the return of assemblages of species.

\section{Methods}

\section{Study area}

Our study region was a 150 x $120 \mathrm{~km}$ agricultural area within the South-west Slopes region of New South Wales, south-eastern Australia (Figure 1). The South-west Slopes was formerly dominated by temperate native woodland (Lindenmayer et al 2010a), but has been cleared of an estimated $85 \%$ of its original cover to facilitate livestock grazing and cereal cropping. As a result, the South-west Slopes region has been the target of major planting programs (Cunningham et al 2014).

We focused on 64 areas of replanted native vegetation and 33 woodland remnants on 27 farms in our study region. The plantings we examined were located on the same farms as the benchmark woodland remnants (Figure 1). This enabled us to account for potential farmlevel heterogeneity effects on fauna associated with farm-level management practices such as 
fox-baiting, chemical spraying and fertilizer application (see Barrett 2000). Attributes such as patch size and shape for plantings and remnants were matched as far as practicable on farms.

\section{Plantings}

Our 64 planted native vegetation sites were characterized by a mix of local endemic and exotic Australian ground cover, understorey, and overstorey plant species. Most plants were typically spaced $2 \mathrm{~m}$ apart, but there was not a standard set of spacing and plant species composition protocols applied in revegetation efforts. The area of plantings ranged from 0.360.3 ha, width ranged from 10-300 m, and perimeter ranged from 412-3802 m. Of the 64 plantings, 37 exceeded 6 years old and 22 were 10-20 years old at the start of this study (2002).

We completed detailed surveys of vegetation structure and composition in the plantings including the total number of stems, canopy depth and height, and the percentage cover in the understorey, midstorey and overstorey. We measured these variables in three 20 x $20 \mathrm{~m}$ plots at 0,100 and $200 \mathrm{~m}$ points along a permanent transect at each site on three occasions: 2002 (at the establishment of the study), 2008 and 2013. To obtain a site-level description of the vegetation features, we aggregated plot-level data to the site level. We defined understorey, midstorey and overstorey based on height; the overstorey was vegetation exceeding 10 meters in height, midstorey was 2-10 m in height, and understorey was woody vegetation less than 2 $m$ in height.

\section{Woodland remnants as benchmark sites}

We compared the avifauna of plantings against 33 temperate eucalypt woodland remnants dominated by the following tree species: white box (Eucalyptus albens), yellow box (E. melliodora), Blakely's red gum (E. blakelyi), grey box (E. microcarpa), red stringybark (E. macrorhyncha), mugga ironbark (E. sideroxylon) and red box (E. polyanthemos). Remnant 
size ranged from $0.5-53.8 \mathrm{ha}$, width from $20-480 \mathrm{~m}$, and perimeter from $603-3797 \mathrm{~m}$. Other attributes of these remnants are summarized by Montague-Drake et al. (2009).

\section{Bird surveys}

We gathered bird data using repeated five-minute point interval counts at $0 \mathrm{~m}, 100 \mathrm{~m}$ and 200 $\mathrm{m}$ along the fixed transect at each site. We completed winter and spring surveys because the assemblages of birds can be markedly different at these times, with winter latitudinal and altitudinal migrants (e.g. the flame robin; see Online Resource 1 for scientific names) absent in spring when latitudinal migrants (e.g. restless flycatcher) are present. For plantings, we completed spring counts at 39 sites in 2002, 46 in 2004, and 64 in 2006, 2008, 2009 and 2011, and 60 in 2013. This resulted in a total of 401 site-by-year observations (hereafter termed "surveys"). For winter surveys of plantings, we completed counts at 46 sites in 2004, and 64 in 2007, 2008 and 2011, and 60 in 2013, giving 298 surveys. Our bird data for the remnants were based on surveys completed in spring at 29 sites in 2002, 33 in 2004, 2006, 2008, 2009, 2011, and 32 in 2013, giving 226 site-by-year observations (viz: surveys). In winter, there were 33 sites in 2004, 2007, 2008, 2011 and 32 in 2013, giving 164 surveys. The number of sites surveyed in any given year varied depending upon access to farms and paddock conditions. The total dataset for our study comprised 1089 surveys and 6534 point counts.

For each point-interval count in plantings and remnants, an observer recorded all bird species seen or heard within the site and the detection of each individual bird was assigned to one of several distance categories from the centre of a plot; 0-25 m, 25-50 m and $>50 \mathrm{~m}$. We restricted our analyses to detections made within $50 \mathrm{~m}$ of the centre of a field plot point. In any given year and season, a site was surveyed by two observers on different days. We did not undertake surveys during poor weather (rain, high wind, fog or heavy cloud cover). We observed these protocols to reduce the effects of observer heterogeneity and day effects 
174 (Lindenmayer et al 2009). We elected not to complete detectability/occupancy analyses in 175 our study of individual species for a range of key reasons. Most importantly, past detailed statistical analyses on the topic of detection/occupancy (e.g. Welsh et al 2013) suggests that

177 the current statistical methods for detection/occupancy may not improve model fit and in 178 some cases can make the outcomes worse. Moreover, it is currently not possible to determine when detection occupancy improves model fit and when it does not (Welsh et al 2015).

\section{Bird life-history analyses}

We collated data on bird species traits to address Question 5 on links between temporal changes in species' identities within plantings linked with particular kinds of life-history attributes. We summarized data on life-history (habitat, diet, foraging substrate, movement, social system, nesting and mating behaviour, and reproductive output), and morphological (body mass and relative wing length) traits (see Online Resource 2) (Handbook of Australian and New Zealand Birds 1990-2006; BirdLife Australia 2014). These traits are thought to reflect the ability of species to respond to environmental change (Luck et al 2012). For analysis of winter data, we excluded four traits that are most applicable to the spring breeding season; nest type, nest height, mating behaviour and reproductive output.

Statistical analyses

To assess whether time since planting was a proxy for change in vegetation structure in plantings, we modelled eight vegetation measures (Table 1), fitting a linear effect of time since planting using the generalized linear mixed model facilities of GenStat (VSNi 2013).

We included a random effect of site nested within farm to take account of the repeated measurements at each site. For count and percentage measurements, we used a negative binomial distribution with a log link function because there was substantial over-dispersion in the data. 
To address Question 1 about temporal changes in species richness, we modelled species richness for planted and remnant sites, again using negative binomial regression with a linear effect of time since planting on the log scale. We included a random effect of site nested within farm, a fixed effect of calendar time (defined as the number of years since 2002 when the first measurements were made), and a fixed effect representing the type of site (remnant or planting). For remnant sites, we set time since planting to zero; there was no loss of generality because of the latter fixed effect. We fitted models of the change in species richness associated with increasing length of time since planting, adjusting for any effect of calendar time, which was estimated from planted and remnant sites together. For planted sites, we fitted a time trend for bird species richness with time since planting. Question 2 explored relationships between temporal changes in bird species richness and planting geometry (width, length, area and perimeter). For width effects, we examined the smallest average dimension of the planting and remnant sites. We modelled the effect of width first as a linear trend, then explored non-linearity using a four-dimensional smooth (a generalized linear additive model with a smoothing spline) and as a two-level factor with boundaries suggested by the smooth line. We also examined other available measurements of geometry (length, area and perimeter).

Question 3 examined temporal changes in individual species in plantings. We focussed on species observed in $>10 \%$ of the surveys completed in spring or winter; we excluded other species as we deemed there were insufficient data on them to facilitate detailed statistical analyses. We defined a factor by grouping surveys into three approximately equalsized groups by time since planting: $<8,8-16$, and $>16$ years. For winter and spring separately, we fitted a generalized linear mixed model for occurrence of each species in planted sites and in remnant sites. The model included random effects to account for repeated measurements on sites within farms, and a fixed effect of the three-level factor representing 
time since planting, fitted on the logistic scale (using the GLMM procedure of GenStat). We included fixed effects for calendar time and type of site (remnant or planting), and without loss of generality set "time since planting" as zero for remnant sites. We investigated the trends in time further for individual species with the largest effects evident from the previous analysis, by fitting a linear trend (on the logit scale) to the relationship with time since planting as a continuous variable. We fitted models of the change in occurrence of each species associated with increasing length of time since planting, adjusting for any effect of calendar time, which was estimated from planted and remnant sites together.

We also explored changes in the composition of the whole bird assemblage over time using multivariate ordination. We used principal coordinate analysis based on an among-site similarity matrix derived from bird species presence-absence data, and using the Jaccard similarity metric. However, we found that the best coordinate identified by this method accounted for less than $5 \%$ of the variation in our data, and the next best $3 \%$. We also employed Correspondence Analyses (Greenacre 2007) as an alternative method to explore the patterns of community composition but the largest root accounted for only $2.9 \%$ of the variation in our data in spring and $3.5 \%$ in winter. We therefore concluded these approaches did not lead to any useful characterization of changes in bird assemblage composition. We instead focused on quantifying temporal changes in the occurrence of individual bird species. Question 4 focused on relationships between temporal changes in the occurrence of individual bird species and planting geometry. Here we employed the same statistical approaches as those used to answer Question 2 but focused on individual species occurrence rather than overall species richness (see above).

To address Question 5 concerning the links between life-history attributes and plantings, we divided bird species into two groups for each of eleven different species traits. These traits were habitat type (open country vs woodland), diet, foraging strategy, movement, 
social system, nest type, nest height, mating system, reproductive output, body mass, relative wing length (see Online Resource 2). We modelled species richness within each trait group, as for total species richness, fitting the fixed effect of time since planting and the random effects of site nested within farm. As most of the life-history variables were categorical, we adopted a parsimonious approach to our analyses based on dichotomies between groups of categories within a given life-history variable rather than attempting to construct linear effects. We assessed each attribute in turn, ignoring the other attributes because of potential confounding between traits (e.g. larger bodied birds tend to have more eggs). Thus, we did not include all the traits in the same model.

All p-values stated in the results are derived from Wald tests applied to the relevant generalized linear mixed model.

\section{Results}

We recorded 146 bird species in spring and 119 in winter (yielding 151 species in total; see Online Resource 1). Of these, 109 species in spring (84 species in winter) were common to plantings and remnants, with an additional 12 (8) in remnants and 25(27) in plantings. Many species were seen rarely: 80 in spring and 95 in winter were observed in less than $1 \%$ of the 627 (462) site-year surveys; 31 species (23) were observed in more than $10 \%$ of the surveys. The plantings were characterized by temporal changes in vegetation attributes. Of the eight vegetation measures investigated, we identified a significant increase in half of them (Table 1). For example, canopy height increased by $0.38 \mathrm{~m}$ per year on average, compared to a mean height of $10 \mathrm{~m}$. The percentage overstorey cover also increased over time, but not in the mid- or understorey. All of these increases were approximately linear over the 30 -year range of our dataset (on the log scale for count or proportion measurements), except for canopy depth, which plateaued after about 15 years. These variables were, of course, inter- 
correlated. Given these results, we considered that time since planting was a reasonable and statistically robust proxy for change in vegetation structure in plantings.

\section{Question 1. Does bird species richness in plantings change over time?}

In remnants, mean bird species richness was 12.6 in spring (s.d. 4.7) and 9.5 in winter (s.d. 3.4). In plantings, values for mean bird species richness were 12.7 in spring (s.d. 4.5) and 10.1 in winter (s.d. 4.0). One site was planted 40 years before our first surveys, whereas the next oldest was 16 years. Averaging over years, this older site supported $\sim 6$ more species both in spring and winter than the mean over the other sites. We excluded this outlier to avoid a single site dominating the results.

We found no evidence of change in species richness with calendar time in spring or winter $(p>0.81)$. There was evidence of an increase in species richness in winter with time since planting, $1.3 \%$ per year on average ( $95 \%$ CI $0.1-2.6 \%$ ), but no equivalent change in spring ( $\mathrm{p}=0.22$ ) (Figure 2; see Online Resource 3 for detailed results). This estimated rate of increase in winter starting from, for example, 10 species, would give one extra species after seven years, and seven extra after 40 years, if the trend were extrapolated.

\section{Question 2: Do planting attributes influence temporal changes in bird species richness?}

We found a positive linear relationship between bird species richness and planting width in spring $(\mathrm{p}<0.001)$ and winter $(\mathrm{p}=0.04)$; there was no significant similar relationship for remnant sites $(\mathrm{p}=0.21)$. Fitting a four-dimensional smooth curve provided evidence that the slope of the relationships in spring decreased to a plateau at about $75 \mathrm{~m}$ planting width; in winter there was no evidence of a nonlinear effect with width (Figure 3). Figure 6 in Online Resource 4 shows the smooth curves fitted for remnant sites. We therefore summarized the effect of width by fitting a three-level factor discriminating between narrow $(<25 \mathrm{~m})$, intermediate $(25-75 \mathrm{~m})$ and wide $(>75 \mathrm{~m})$ plantings instead of the linear effect. In spring, wide plantings supported, on average, $18 \%$ greater bird species richness than narrow ones 
297

298

299

300

301

302

303

304

305

306

307

308

309

310

311

312

313

314

315

316

317

318

319

( $95 \%$ confidence interval $3-39 \%, p=0.02)$; in winter the average increase was $16 \%(1-36 \%$, $\mathrm{p}=0.04)$. There was no significant interaction between planting width and planting time $(p>0.70)$.

Of the other plot measurements, only area had a significant relationship with species richness ( $\mathrm{p}=0.02)$, and that was not as strong as the relationship between width and species richness. There was a strong positive correlation of area with width $(\mathrm{r}=0.61, \mathrm{p}<0.001)$.

Question 3. Are there changes in the occurrence of particular individual species over time?

We quantified the mean occurrence of each bird species in planted sites, tabulated into three groups according to time since planting (viz: $<8,8-16$, and $>16$ years) (Figure 4; detailed results are presented in Online Resource 3). In spring, the largest change with increasing time since planting was the increase in occurrence of the red wattlebird, which occurred at $22 \%$ of sites planted less than eight years before, rising to $51 \%$ of sites planted longer than 16 years before $(\mathrm{p}=0.007)$. Other species whose occurrence in plantings increased significantly over time were the white-winged chough ( 6 to $27 \%, \mathrm{p}=0.004)$, weebill ( $7 \%$ to $24 \%, \mathrm{p}=0.03$ ) and the yellow thornbill ( $8 \%$ to $25 \%, \mathrm{p}=0.02$ ). Conversely, the occurrence of the striated pardalote decreased from $65 \%$ to $39 \%(\mathrm{p}=0.01)$, as did the willie wagtail ( $89 \%$ to $68 \%$, $\mathrm{p}=0.01)$.

In winter, the occurrence of the red wattlebird increased significantly with time since planting, from $23 \%$ to $53 \%$ across the duration of our study $(\mathrm{p}=0.006)$. There also were significant increases of the grey fantail ( $2 \%$ to $38 \%, \mathrm{p}<0.001)$, yellow thornbill ( $7 \%$ to $37 \%$, $\mathrm{p}=0.002)$ and superb fairy-wren ( $41 \%$ to $79 \%, \mathrm{p}=0.01)$, and a decrease in the crested pigeon $(53 \%$ to $32 \%, \mathrm{p}=0.05)$.

In comparison to the plantings, the largest changes in species in remnants over calendar time (grouped as 2002-6, 2007-9 and 2011-13) were decreases in occurrence of the striated 
pardalote and red-rumped parrot in winter, and of the noisy miner in spring (all highly significant, $\mathrm{p}=0.001$; Figure 5).

To investigate changes in individual species in more detail, we selected the species with the largest effects identified above, three species in spring and four in winter, and fitted linear trends with both calendar time and time since planting (the same explanatory model as for species richness in Question 1). There was no evidence of a trend with calendar time ( $>0.20)$ for any of the three species in spring. The trends with time since planting were substantial (first three panels of Figure 7 in Online Resource 5), but statistically significant only for the red wattlebird $(\mathrm{p}=0.02)$. In winter for the red wattlebird, there was again no apparent trend with calendar time ( $p>0.20)$, but a significant increase with time since planting $(p<0.001$; first panel of Figure 8 of Online Resource 5). However, for the other three species (second to fourth panels of Figure 8 of Online Resource 5), the apparent increase with time since planting (Figure 4) appears to be a result of an overall trend with calendar time (significant in all cases, $\mathrm{p}<0.01$ ); none of the three trends with time since planting (actually negative, after adjusting for the effect of calendar time) was significantly different from zero $(\mathrm{p}>0.20)$. Figures 9 and 10 in Online Resource 5 show the effects of calendar time similar to those for time since planting in Figures 7 and 8.

\section{Question 4: Do planting attributes influence temporal changes in occurrence of individual}

\section{bird species?}

We identified significant planting width effects for only one individual species, the grey fantail. Its odds of occurrence in winter were 3.0 times greater in wide $(>75 \mathrm{~m})$ plantings than in narrow $(<25 \mathrm{~m})$ plantings $(95 \%$ CI $1.3-6.9, \mathrm{p}=0.01)$.

\section{Question 5. Are temporal changes in species' identities within plantings linked with} particular kinds of life-history attributes? 
We divided bird species into two classes for each of 11 species traits (Table 2). Examining species richness of these classes in spring revealed a significant positive effect of time since planting for species with "co-operative" mating behaviours. Richness of these species increased on average by $2.8 \%$ per annum (95\% CI: -0.1 to $5.6 \%$ ) (Table 2). In comparison, time since planting had a significant negative effect on species with high reproductive output (clutch size multiplied by number of broods per season). Richness of these species decreased on average by $-0.9 \%$ per annum (95\% CI: -1.8 to $0 \%)$.

In winter, time since planting had a significant positive effect on species that (1) are associated with woodland habitat, (2) feed primarily on invertebrates, (3) forage in the understorey or canopy, (4) are migratory or dispersive, (5) commonly occur in small groups, (6) have low mass, and (7) have long relative wing lengths (Table 2). Increases ranged from $1.7 \%$ per annum for long relative wing length to $4.3 \%$ for species associated with woodland habitat.

Investigating so many effects (18 groupings) is likely to lead to one or two significant effects by chance, but it is clear that many of the traits are associated with an increase in richness in winter (and, of course, these effects are inter-correlated). For instance, the estimate of $4.3 \%$ increase per year for woodland species corresponded to a doubling in species richness in 17 years after planting. However, the mean migratory species richness in winter was only 2.3 , so that doubling would increase the mean to 4.6 woodland migratory species in that time.

\section{Discussion}

\section{Temporal changes in species richness and the occurrence of individual species}

We observed limited increases in bird species richness in plantings over time, and this was only in winter and not in spring. Even in winter, the accumulation of species was relatively 
modest with one additional species per seven years of planting maturation. The paucity of marked temporal increases in bird species richness associated with increased planting age was consistent with the strong evidence we obtained for significant temporal changes in the occurrence of individual species in plantings. That is, gains in species were largely countered by losses of other species over time and this was reflected in limited changes in overall species richness.

We identified few differences in temporal changes in bird species richness between remnants and plantings. In contrast, there were major differences in the occurrence of individual bird species. Based on individual species responses, it remains unclear whether the trajectory of post-establishment recovery of replanted areas will approach that of remnant woodland "reference" sites or whether it is on another trajectory altogether (see also Wilkins et al. 2003; Brady and Noske 2009). We are, however, acutely aware that our study has been underway for 12 years and it may take much longer before bird assemblages in plantings become similar to those typical of remnant woodlands.

The mechanisms underlying the temporal patterns of bird species richness and individual species occurrence in plantings remain unclear. However, it is possible that changes in vegetation structure altered the habitat suitability for particular species of birds and this, in turn, was a factor underpinning temporal changes in individual species occurrence. There is a large literature on relationships between bird diversity and habitat structure (MacArthur and MacArthur 1961) (Morrison et al 2006) (Barton et al 2014). Other factors associated with time, like the chance that dispersing birds will locate and settle in plantings (Barrett et al. 2008) also may have influenced our findings for bird species richness, although limited (if any) temporal increases in species richness suggest that new arrivals may displace earlier colonists. 
We uncovered strong evidence of marked temporal change in the occurrence of particular bird species in plantings, the various ordination techniques we employed provided no compelling evidence for simple combinations of species that characterized plantings of different ages. Dominant axes or roots from these analyses explained only a small amount of variation in our data. Large variation in bird species occurrence between sites and within sites over time may explain the paucity of community composition effects.

Finally, a key caveat associated with this study is that our focus was on a single (albeit species-rich) group. It is unclear whether our results for birds will be an accurate reflection of the temporal responses of other groups such as invertebrates (Gibb and Cunningham 2010) or reptiles (Cunningham et al 2007). Therefore, assessing the overall effectiveness of restoration efforts should entail analyses of a range of taxa beyond a single group such as birds.

\section{Planting geometry and bird responses}

Our analyses indicated that of the various measures of planting geometry we examined, width had the strongest effects on bird species richness; overall, wider plantings tended to support significantly more bird species than narrow ones. This result was expected as it generally conforms to predictions from landscape ecology theory with wider plantings expected to have more interior vs edge habitat suitable for animal occupancy of sites (Lindenmayer and Hobbs 2007; Collinge 2009). However, only one species (the grey fantail) exhibited a significant planting width effect, suggesting the majority of bird taxa are tolerant of edge environments typical of most plantings in the agricultural environments in this study. This is broadly congruent with other findings from this investigation indicating there were no significant relationships between bird species richness and the width of woodland remnants (i.e. our socalled "benchmark" sites). Finally, we found no statistical support for our hypothesized response at the outset of this study that wider plantings should be characterised by faster rates of increase in species richness than narrow plantings. This result may be related to the fact 
that there was only relatively limited temporal change in overall bird species richness and such effects therefore spanned plantings of a range of widths; viz: those that were narrow, intermediate and wide.

\section{Planting age and bird life-history attributes}

We found evidence that changes in the identity of birds occupying plantings of different age can be anticipated in a broadly predictable way based on key life-history attributes, particularly movement patterns and habitat and diet specialisation. For example, the occurrence of woodland-associated species, insectivores, understorey and canopy foragers, highly mobile (migratory and those with long relative wing lengths) species, solitary or paired birds, and arboreal cup-nesters with low reproductive output.

Some of the bird life history responses were generally expected, such as the increase in woodland-associated bird species with increasing planting age. Other responses may be broadly linked with temporal changes in vegetation structure of plantings (see Table 1) and, in turn, the suitability of nesting sites for some species (see Beruldsen 2003), as well as the suitability of foraging substrates via changes in invertebrate assemblages associated with plantings of different ages (Gibb and Cunningham 2010) (and hence prey for avian insectivores). Migratory species were also more likely to increase in occurrence in older plantings. Many migratory species in Australia (including winter migrants) often return to the same areas year after year (Handbook of Australian and New Zealand Birds 1990-2006) and these species are especially vulnerable to environmental change in their wintering habitat (Runge et al 2014). It may therefore be some years after a planting has been established for the offspring of such species to find revegetated areas.

\section{Implications for management and biodiversity conservation}

We found that replanted areas of different ages supported different species of birds. Some species associated with young plantings may drop out of restored ecosystems if new plantings 
are not continuously added over time. We therefore suggest that plantings of a range of ages will be needed on a farm to provide a range of suitable habitats for different native bird species. However, our findings also suggest there is value in ensuring there are long established plantings on farms. This is because such plantings will continue to accumulate species over time (in winter).

A general recommendation for woodland restoration in Australia (and elsewhere) has been to promote the establishment of wider areas of planted vegetation (Munro and Lindenmayer 2011). Our results generally support these recommendations as wider plantings support significantly greater levels of bird species richness than narrow plantings. However, narrow plantings are clearly not without value as indicated by the fact that we identified only one individual species that was sensitive to the effects of planting width.

Finally, we found strong evidence to suggest that the avifauna of plantings is markedly different from that of remnants, even many years after planting establishment. It remains unclear when (or even if) the bird fauna of plantings may begin to resemble that of woodland remnants. Such differences underscore the value of maintaining different broad structural kinds of vegetation on a farm to provide suitable habitat for a suite of native bird species.

\section{Acknowledgments}

This project was supported through grants from the Australian Research Council, Murray Local Land Services and Riverina Local Land Services. Field assistance was provided by D. Blair, L. McBurney, C. MacGregor, D. Florance and G. Kay. C. Shepherd assisted with manuscript preparation.

\section{References}

Aronson J, Alexander S (2013) Ecosystem restoration is now a global priority: Time to roll up our sleeves. Restor Ecol 21:293-296 
Barnagaud J-V, Barbaro L, Papaïx J, Deconchat M, Brockerhoff EG (2014) Habitat filtering by landscape and local forest composition in native and exotic New Zealand birds. Ecology 95:78-87

$$
\text { Barrett G (2000) Birds on farms: Ecological management for agricultural sustainability. }
$$
Wingspan 10:1-16

$$
\text { Barrett GW, Freudenberger D, Drew A, Stol J, Nicholls AO, Cawsey EM (2008) }
$$

Colonisation of native tree and shrub plantings by woodland birds in an agricultural landscape. Wildlife Res 35:19-32

Barton PS, Ikin K, Smith AL, MacGregor C, Lindenmayer DB (2014) Vegetation structure moderates fire effects on bird assemblages in a heterogeneous landscape. Landscape Ecol 29:703-714
Beruldsen G (2003) Australian birds. Their nests and eggs. G. Berulsen, Brisbane BirdLife Australia 2014. Birds in backyards bird finder. Available at http://www.Birdsinbackyards.Net/finder/all-species.

\section{Brady CJ, Noske RA (2009) Succession in bird and plant communicaties over a 24-year} chronosequence of mine rehabilitation in Australian monsoon tropics. Restor Ecol 18:855864

Bullock JM, Aronson J, Newton AC, Pywell RF, Benayas JMR (2011) Restoration of ecosystem services and biodiversity: Conflicts and opportunities. Trends Ecol Evol 26:541549

Catterall CP, Freeman AN, Kanowski J, Freebody K (2012) Can active restoration of tropical rainforest rescue biodiversity? A case with bird community indicators. Biol Conserv 146:5361

Clewell AF, Aronson J (2007) Ecological restoration: Principles, values, and structure of an emerging profession. Island Press, Washington, DC

Collinge SK (2009) Ecology of fragmented landscapes. The Johns Hopkins University Press, Baltimore

Cristescu RH, Frere C, Banks PB (2012) A review of fauna in mine rehabilitation in Australia: Current state and future directions. Biol Conserv 149:60-72 Cunningham RB, Lindenmayer DB, Barton P, Ikin K, Crane M, Michael D, Okada S, Gibbons P, Stein J (2014) Cross-sectional and temporal relationships between bird occupancy and vegetation cover at multiple spatial scales. Ecol Appl 24:1275-1288 
501 Cunningham RB, Lindenmayer DB, Crane M, Michael D, MacGregor C (2007) Reptile and

502

503

504

505

506

507

508

509

510

511

512

513

514

515

516

517

518

519

520

521

522

523

524

525

526

527

528

529

530

531

532

533

534

arboreal marsupial response to replanted vegetation in agricultural landscapes. Ecol Appl $17: 609-619$

Diamond J (1986) Overview: Laboratory experiments, field experiments and natural experiments. In: Diamond J and Case TJ (eds.) Community ecology. Harper and Row, New York, pp 3-22

Dobson AP, Bradshaw AD, M. BAJ (1997) Hopes for the future: Restoration ecology and conservation biology. Science 277:515-522

Dornelas M, Gotelli NJ, McGill B, Shimadzu H, Maues F, Sievers C, Magurran AE (2014) Assemblage time series reveal biodiversity change but not systematic loss. Science 344:296299

Fischer J, Lindenmayer DB, Montague-Drake R (2008) The role of landscape texture in conservation biogeography: A case study on birds in south-eastern Australia. Divers Distrib $14: 38-46$

Ford HA, Walters JR, Cooper CB, Debus SJ, Doerr VA (2009) Extinction debt or habitat change? Ongoing losses of woodland birds in north-eastern New South Wales, Australia. Biol Conserv 142:3182-3190

Fox BJ, Taylor JE, Thompson PT (2003) Experimental manipulation of habitat structure: A retrogression of the small mammal succession. J Anim Ecol 72:927-940

Gibb H, Cunningham SA (2010) Revegetation of farmland restores function and composition of epigaeic beetle assemblages. Biol Conserv 143:677-687

Greenacre MJ (2007) Theory and applications of correspondence analysis. Academic Press, Orlando, Florida

Hajkowicz S (2009) The evolution of Australia's natural resource management programs: Towards improved targeting and evaluation of investments. Land Use Pol 26:471-478 Handbook of Australian and New Zealand Birds (1990-2006) Handbook of Australian, New Zealand and Antarctic birds, volumes 1-7. Oxford University Press, Melbourne Hanspach J, Fischer J, Ikin K, Stott J, Law BS (2012) Using trait-based filtering as a predictive framework for conservation: A case study of bats on farms in southeastern Australia. J Appl Ecol 49:842-850

Herrick JE, Schumna GE, Rango A (2006) Monitoring ecological processes for restoration projects. J Nat Conserv 14:161-171

Hilderbrand RH, Watts AC, Randle AM (2005) The myths of restoration ecology. Ecol Soc 10:Art. 19. [online] URL: http://www.ecologyandsociety.org/vol10/iss1/art19/ 
535

536

537

538

539

540

541

542

543

544

545

546

547

548

549

550

551

552

553

554

555

556

557

558

559

560

561

562

563

564

565

566

567

Howes A, R. MN, Loyn RH, Kath J, Bowen M, McAlpine C, Maron M (2014) Foraging guild perturbations and ecological homogenization driven by despotic native bird species. Ibis $156: 341-354$

Johnson EA, Miyanishi K (2008) Testing the assumptions of chronosequences in succession. Ecol Lett 11:419-431

Kimball S, Lulow M, Sorenson Q, Balazs K, Fang Y-C, Davis SJ, O'Connell M, Huxman TE (2015) Cost-effective ecological restoration. Restor Ecol 23:800-810

Kinross C, Nicol H (2008) Responses of birds to the characteristics of farm windbreaks in central New South Wales, Australia. Emu 108:139-152

Langlands PR, Brennan K, Framenau VW, Main BY (2012) Predicting the post-fire responses of animal assemblages: Testing a trait-based approach using spiders. J Anim Ecol 80:558-568

Lindenmayer DB, Bennett AF, Hobbs RJ (eds.) 2010a. Temperate woodland conservation and management. CSIRO Publishing, Melbourne

Lindenmayer DB, Blanchard W, Tennant P, Barton P, Ikin K, Mortelliti A, Okada S, Crane M, Michael D (2015) Richness is not all: How changes in avian functional diversity reflect major landscape modification caused by pine plantations. Divers Distrib 21:836-847

Lindenmayer DB, Burns E, Thurgate N, Lowe A (eds.) 2014. Biodiversity and environmental change: Monitoring, challenges and direction. CSIRO Publishing, Melbourne

Lindenmayer DB, Fischer J (2006) Habitat fragmentation and landscape change. Island Press, Washington, D.C.

Lindenmayer DB, Hobbs R (eds.) 2007. Managing and designing landscapes for conservation: Moving from perspectives to principles. Blackwell Scientific, Oxford Lindenmayer DB, Knight EJ, Crane MJ, Montague-Drake R, Michael DR, MacGregor CI (2010b) What makes an effective restoration planting for woodland birds? Biol Conserv 143:289-301

Lindenmayer DB, Wood JT, MacGregor C (2009) Do observer differences in bird detection affect inferences from large-scale ecological studies? Emu 109:100-106

Luck G, Lavorel S, McIntyre S, Lumb K (2012) Improving the application of vertebrate traitbased frameworks to the study of ecosystem services. J Anim Ecol 81:1065-1076 MacArthur RH, MacArthur JW (1961) On bird species diversity. Ecology 42:594-598 Menke S, Gaulke E, Hamel A, Vachter N (2015) The effects of restoration age and prescribed burns on grassland ant community structure. Environ Entomol 44:1336-1347 
568

569

570

571

572

573

574

575

576

577

578

579

580

581

582

583

584

585

586

587

588

589

590

591

592

593

594

595

596

597

598

599

600

601

Menz M, Dixon K, Hobbs R (2013) Hurdles and opportunities for landscape-scale restoration. Science 339:526-527

Montague-Drake RM, Lindenmayer DB, Cunningham RB (2009) Factors affecting site occupancy by woodland bird species of conservation concern. Biol Conserv 142:2896-2903 Morrison ML, Marcot BG, Mannan RW (2006) Wildlife-habitat relationships. Concepts and applications. Island Press, Washington, D.C.

Mossman HL, Brown MJH, Davy AJ, Grant A (2012) Constraints on salt marsh development following managed coastal realignment: Dispersal limitation or environmental tolerance?

Restor Ecol 20:65-75

Mouillot D, Graham NA, Villeger S, Mason NW, Bellwood DR (2012) A functional approach reveals community responses to disturbances. Trends Ecol Evol 28:167-177 Munro N, Fischer J, Barrett G, Wood J, Leavesley A, Lindenmayer DB (2011) Bird's response to revegetation of different structure and floristics - are "restoration plantings" restoring bird communities? Restor Ecol 19:223-235

Munro N, Fischer J, Wood J, Lindenmayer DB (2009) Revegetation in agricultural areas: The development of structural complexity and floristic diversity. Ecol Appl 19:1197-1210

Munro N, Lindenmayer DB (2011) Planting for wildlife: A practical guide to restoring native woodlands. CSIRO Publishing, Melbourne

Munro N, Lindenmayer DB, Fischer J (2007) Faunal response to revegetation in agricultural areas of Australia: A review. Ecol Manag Restor 8:199-207

Newbold T, Scharlemann JPW, Butchart SHM, Şekercioğlu CH, Alkemade R, Booth H, Purves DW (2013) Ecological traits affect the response of tropical forest bird species to landuse intensity. Proc R Soc B 280:20122131

Pywell RF, Meek WR, Webb NR, Putwain PD, Bullock, JM (2011) Long-term heathland restoration on former grassland: The results of a 17-year experiment. Biol Conserv 144:16021609

Nichols OG, Grants CD (2007) Vertebrate fauna recolonization of restored bauxite mines key findings from almost 30 years of monitoring and research. Restor Ecol 15:S116-S126 Pulsford S, Lindenmayer DB, Driscoll D (2016) A succession of theories: A framework to purge redundancy in post-disturbance theory. Biol Rev 91:148-167

Reay SD, Norton DA (1999) Assessing the success of restoration plantings in a temperate New Zealand forest. Restor Ecol 7:298-308

Rey Benayas JM, Newton AC, Diaz A, Bullock JM (2009) Enhancement of biodiversity and ecosystem services by ecological restoration: A meta-analysis. Science 325:1121-1124 
602

603

604

605

606

607

608

609

610

611

612

613

614

615

616

617

618

619

620

621

622

623

624

625

626

627

628

629

630

631

632

633

634

635

Runge CA, Martin TG, Possingham HP, Willis SG, Fuller RA (2014) Conserving mobile species. Front Ecol Environ 12:395-402

Selwood K, Mac Nally R, Thomson JR (2009) Native bird breeding in a chronosequence of revegetated sites. Oecologia 159:435-446

Standish RJ, Cramer VA, Wild SL, Hobbs RJ (2007) Seed dispersal and recruitment limitation are barriers to native recolonization of old-fields in Western Australia. J Appl Ecol 44:435-445

Stanturf JA, Palik B, Dumroese RK (2014) Contemporary forest restoration: A review emphasizing function. Forest Ecol Manag 331:292-323

Suding K, Higgs E, Palmer M, Callicott JB, Anderson CB, Baker M, Gutrich JJ, Hondula KL, LaFevor MC, Larson BM, Randall A, Ruhl JB, Schwartz KZ (2015) Committing to ecological restoration. Science 348:638-640

Suding KN (2011) Toward an era of restoration in ecology: Successes, failures and opportunities ahead. Ann Rev Ecol Evol Syst 42:465-487

Tscharntke T, Sekercioglu C, Dietsch TV, Sodhi NS, Hoehn P, Tylianakis JM (2008)

Landscape constraints on functional diversity of birds and insects in tropical agroecosystems. Ecology 89:944-951

Vesk P, Nolan R, Thomson JW, Dorrough JW, Mac Nally R (2008) Time lags in the provision of habitat resources through revegetation. Biol Conserv 141:174-186

VSNi (2013) Genstat 16th edition (computer software), http://www.vsni.co.uk

Watson J, Freudenberger D, Paull D (2001) An assessment of the focal species approach for conserving birds in variegated landscapes in southeastern Australia. Conserv Biol 15:13641373

Welsh AH, Lindenmayer DB, Donnelly CF (2013) Fitting and interpreting occupancy models. PLOS One 8:e52015

Welsh AH, Lindenmayer DB, Donnelly CF (2015) Adjusting for one issue while ignoring others can make things worse. PLOS One 10:e0120817

Wilkins S, Keith DA, Adam P (2003) Measuring success: Evaluating the restoration of a grassy eucalypt woodland on the Cumberland Plain, Sydney, Australia. Restor Ecol 11:489503

World Resources Institute 2011. A world of opportunity. At http://www.Wri.Org/resources/maps/global-map-forest-landscape-restoration-opportunities. Wortley L, Hero J-M, Howes M (2013) Evaluating ecological restoration sucecss: A review of the literature. Restor Ecol 21:537-543 
637 Figure 1 Map of the study region in which plantings and remnants were surveyed for birds

638

639

640

641

642

643

644

645

646

647

648

649

650

651

652

653

654

655

656

657

658 between 2002 and 2013. The circular insets show plantings and remnants on two of the surveyed farms.

Figure 2 Fitted models for changes in bird species richness against time since planting, in winter and spring separately, and observed richness at all sites and years excluding the single site where the planting was more than 40 years old. The thick line shows the fitted trend with time since planting, and the thin line the mean richness in remnants.

Figure 3 Smoothing splines (with 4 d.f.) fitted for the effect of width of plantings on species richness in spring and winter separately.

Figure 4 Changes in occurrence of individual bird species in relation to time since planting, for spring and winter separately. The length of the bars indicate the size of the change and the colour of the bars show the direction of the change. Red bars show species that have increased with time since planting (minimum $\%$ occurrence in the $<8$ years time period and maximum $\%$ occurrence in the $>16$ years period). Blue bars show species that have declined with time since planting (minimum $\%$ occurrence in $>16$ years' period and maximum $\%$ occurrence in the $<8$ years period). Semi-purple bars show species that have increased then declined (red and purple) or declined then increased (blue and purple). The black cross-bars indicated $\%$ occurrence in the 8-16 years time period. Whiskers represent standard errors of the end-points of each bar. Species names are shown in Online Resource 1.

Figure 5 Changes in occurrence of woodland remnant bird species with an occurrence $>10 \%$ of surveys across three groups defined by calendar time in spring and winter separately. (See Figure 4 for further explanation). 
659 Table 1. Vegetation measurements investigated for changes since time since planting. The

660 estimates are the mean value across all years and average increases per year over the 30-year

661 range (excluding the outlying oldest site); the counts and percentages were analysed on the

$662 \log$ scale, so estimates are average percentage increases per year, relative to the previous

663 year.

\begin{tabular}{|l|l|l|}
\hline Measurement & Mean and SD & Estimate and 95\% CI \\
\hline Canopy height & $9.9 \mathrm{~m}(4.1)$ & $0.38 \mathrm{~m}(0.30,0.46)$ \\
\hline Canopy depth & $7.7 \mathrm{~m}(3.3)$ & $0.14 \mathrm{~m}(0.06,0.22)$ \\
\hline No. stems/ha & $935(993)$ & $2.9 \%(-0.5,5.3)$ \\
\hline Basal count & $6.9(4.6)$ & $6.0 \%(4.2,7.9)$ \\
\hline \% Overstorey cover & $16(22)$ & $17 \%(11,24)$ \\
\hline \% Midstorey cover & $26(25)$ & $0.0 \%(-3.7,3.7)$ \\
\hline \% Understorey cover & $3.0(4.1)$ & $-0.3 \%(-4.6,4.2)$ \\
\hline \% Bare earth & $13(17)$ & $-2.1 \%(-6.3,2.3)$ \\
\hline
\end{tabular}


665 Table 2. Species attributes investigated for changes with time since planting. Estimates are

666 the average percentage changes per year in species richness of each class, with $95 \%$

667 confidence limits. Four of the attributes were not investigated in winter, as nesting and

668 breeding behaviour was not considered relevant in that season.

\begin{tabular}{|c|c|c|c|c|c|}
\hline \multirow{2}{*}{$\begin{array}{l} \\
\text { Attribute }\end{array}$} & \multirow[b]{2}{*}{ Class } & \multicolumn{2}{|l|}{ Spring } & \multicolumn{2}{|l|}{ Winter } \\
\hline & & $\begin{array}{l}\text { Estimate and } \\
95 \% \mathrm{CI}\end{array}$ & P-value & $\begin{array}{l}\text { Estimate and } \\
95 \% \mathrm{CI}\end{array}$ & P-value \\
\hline \multirow[t]{2}{*}{ Habitat } & Open country & $-0.8(-1.8,0.2)$ & 0.12 & $-1.0(-2.4,0.3)$ & 0.14 \\
\hline & Woodland & $0.3(-1.2,1.8)$ & 0.74 & $4.3(2.4,6.1)$ & $<0.001$ \\
\hline \multirow[t]{2}{*}{ Diet } & Invertebrates & $-0.2(-1.4,1.0)$ & 0.78 & $2.7(1.2,4.2)$ & $<0.001$ \\
\hline & Other & $-0.7(-1.6,0.3)$ & 0.18 & $0.1(-1.2,1.4)$ & 0.89 \\
\hline \multirow[t]{2}{*}{ Foraging } & $\begin{array}{l}\text { Understorey or } \\
\text { canopy }\end{array}$ & $-0.6(-1.9,0.8)$ & 0.42 & $4.0(2.4,5.6)$ & $<0.001$ \\
\hline & Other & $-0.3(-1.2,0.7)$ & 0.55 & $-1.2(-2.6,0.1)$ & 0.08 \\
\hline \multirow[t]{2}{*}{ Movement } & Sedentary & $-0.7(-1.6,0.2)$ & 0.14 & $-0.2(-1.3,1.0)$ & 0.79 \\
\hline & $\begin{array}{l}\text { Migratory or } \\
\text { dispersive }\end{array}$ & $-0.2(-1.3,1.0)$ & 0.76 & $3.9(2.3,5.4)$ & $<0.001$ \\
\hline \multirow[t]{2}{*}{ Social system } & Small groups & $-0.1(-1.3,1.1)$ & 0.87 & $2.6(1.2,3.9)$ & $<0.001$ \\
\hline & Large groups & $-0.8(-1.7,0.2)$ & 0.11 & $0.2(-0.9,1.4)$ & 0.68 \\
\hline \multirow[t]{2}{*}{ Nest type } & Cup & $-0.7(-1.8,0.4)$ & 0.23 & & \\
\hline & Other & $-0.4(-1.4,0.6)$ & 0.43 & & \\
\hline \multirow[t]{2}{*}{ Nest height } & $<4 \mathrm{~m}$ & $0.4(-1.4,2.2)$ & 0.67 & & \\
\hline & $>4 \mathrm{~m}$ & $-0.7(-1.6,0.3)$ & 0.17 & & \\
\hline Mating behaviour & Co-operative & $2.8(0.1,5.6)$ & 0.04 & & \\
\hline
\end{tabular}




\begin{tabular}{|l|l|l|l|l|l|}
\hline & Other & $-0.7(-1.6,0.2)$ & 0.13 & & \\
\hline Repro. output & Low & $0.7(-0.8,2.3)$ & 0.36 & & \\
\hline & High & $-0.9(-1.8,0.0)$ & 0.05 & & \\
\hline Mass & Low & $-0.6(-1.9,0.7)$ & 0.36 & $2.6(0.9,4.4)$ & 0.002 \\
\hline Relative wing & Short & $-0.3(-1.4,0.8)$ & 0.63 & $0.1(-1.3,1.6)$ & 0.86 \\
\hline length & & $-0.2 .1,0.4)$ & 0.18 & $0.7(-1.1,2.5)$ & 0.47 \\
\hline & & & & & \\
\hline
\end{tabular}




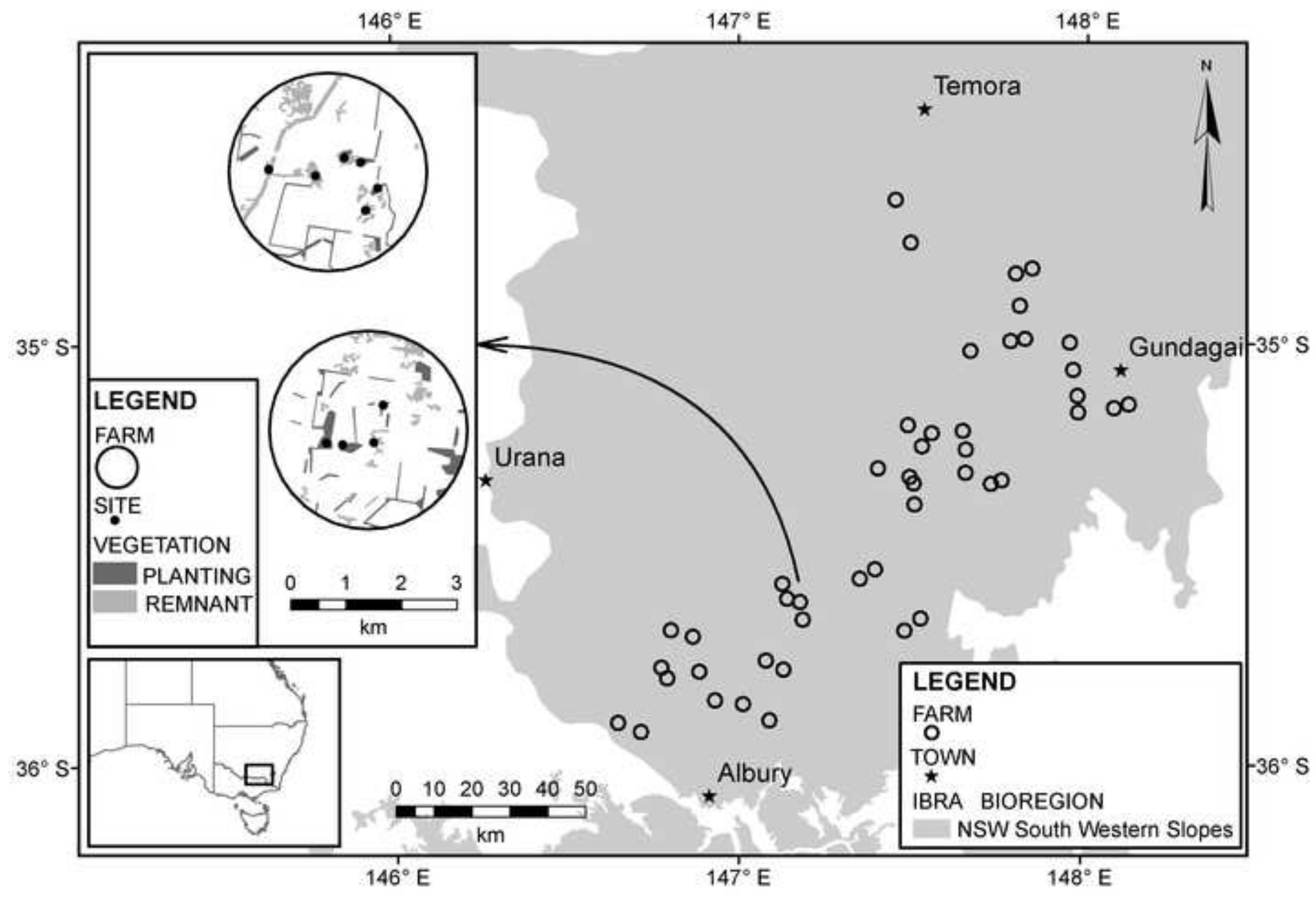




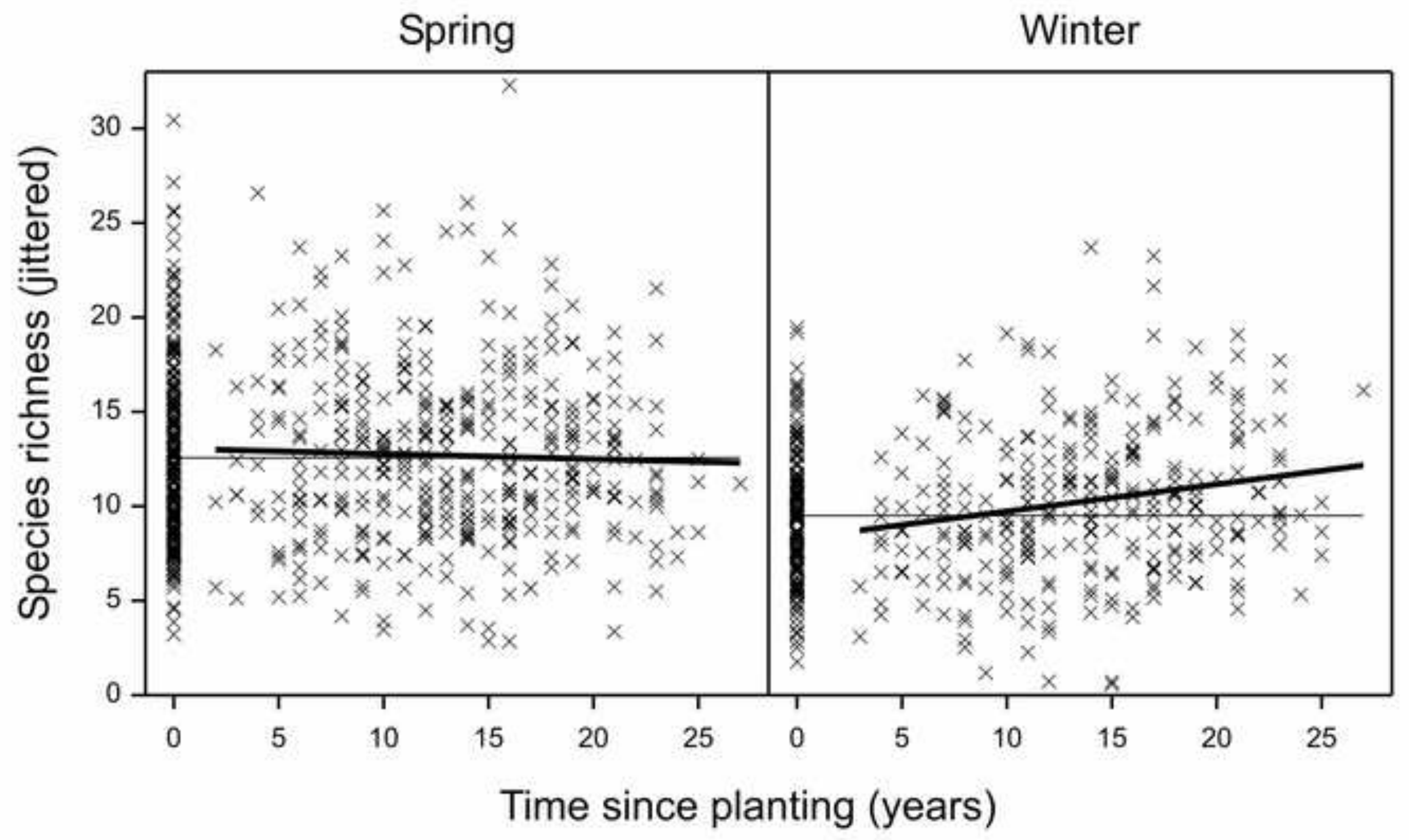




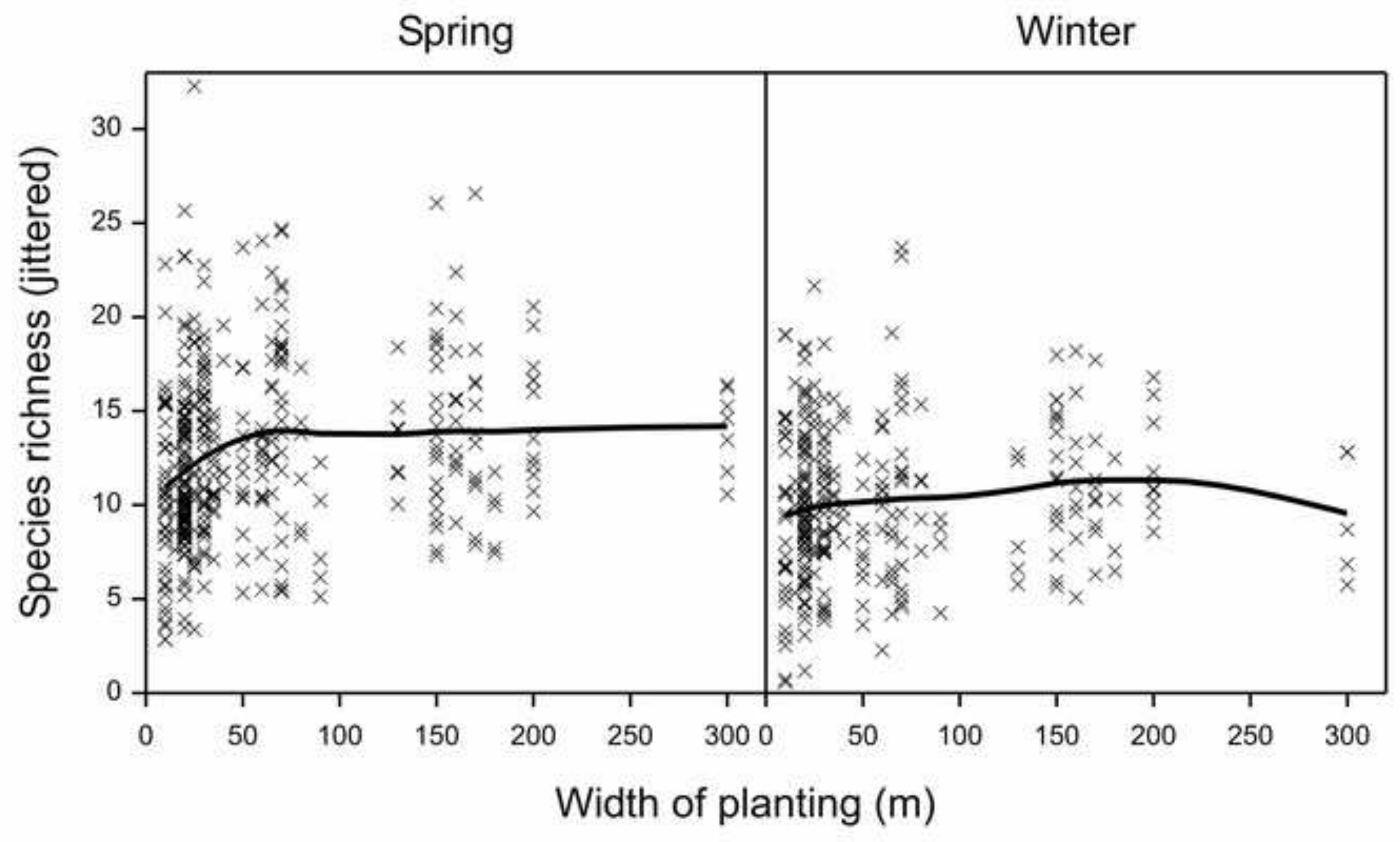




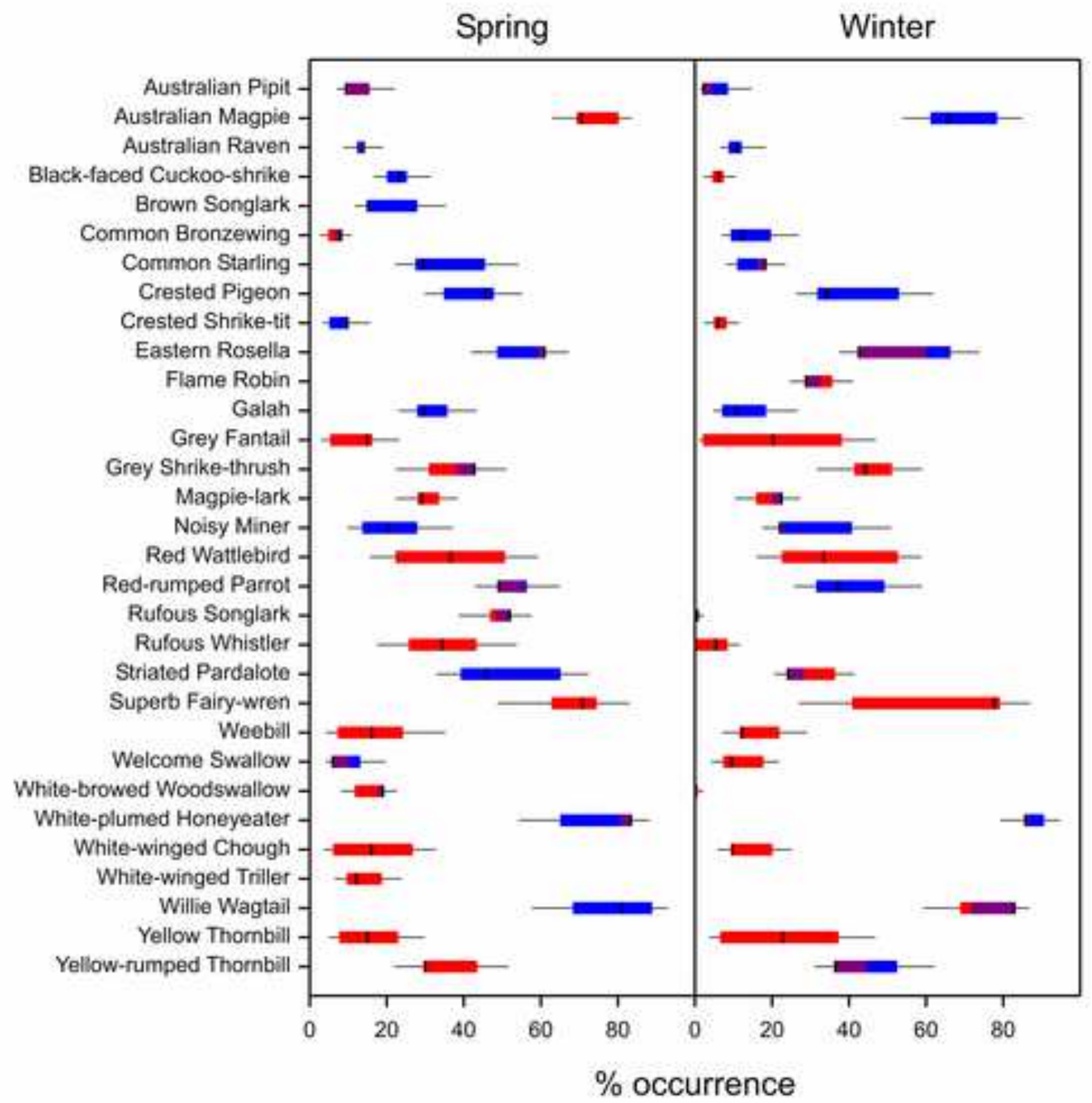




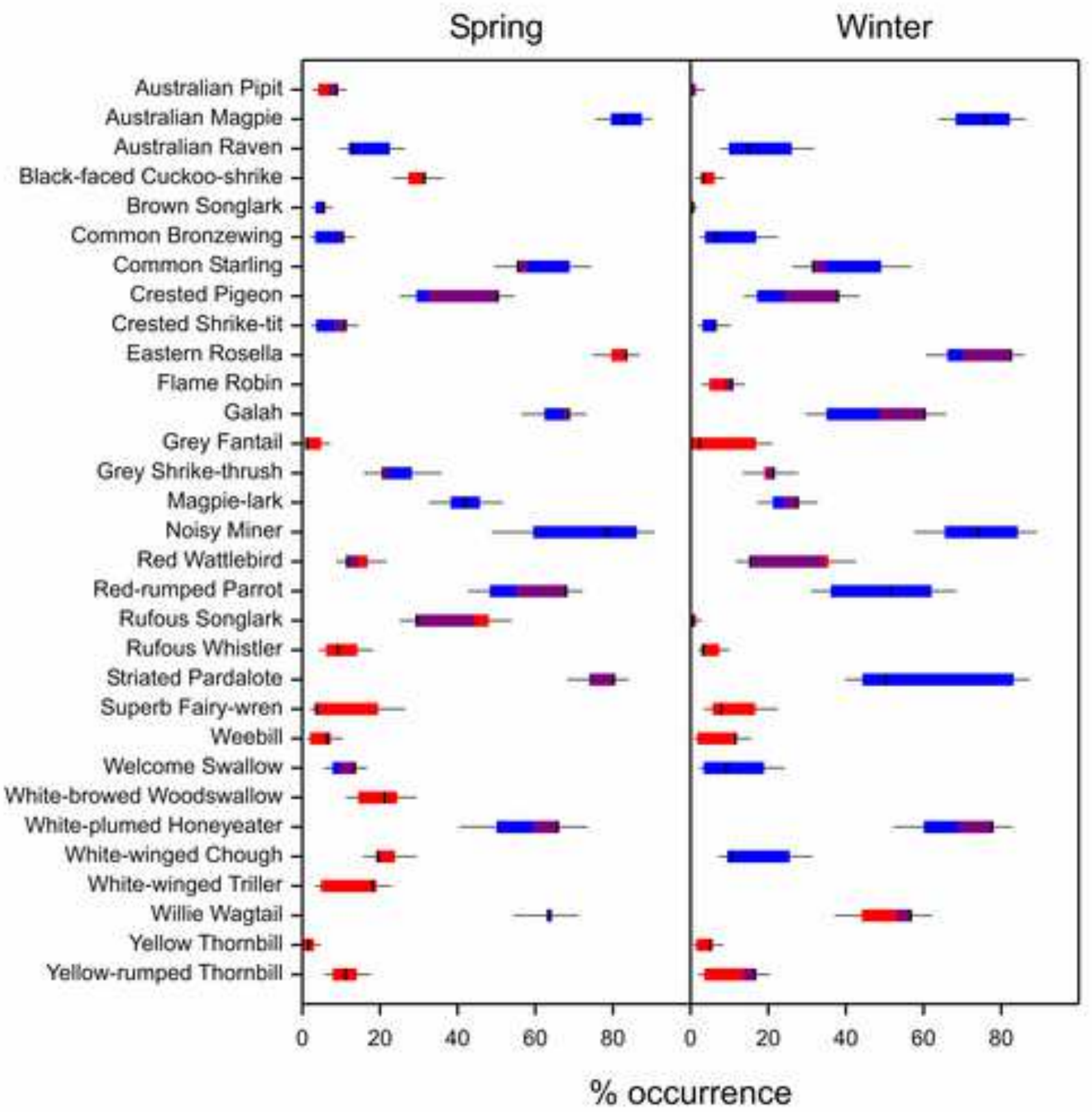

